\title{
ANALISIS KEMAMPUAN MENULIS PANTUN SISWA KELAS V
}

\section{SD}

\author{
Hasri Lebu ${ }^{1}$, Dessy Wardiah ${ }^{2}$, Miftha Indasari ${ }^{3}$ \\ UNIVERSITAS PGRI PALEMBANG, \\ ${ }^{1}$ hasrilebu97@gmail.com ${ }^{2}$ dessywardiah77@gmail.com ${ }^{3}$ mifthaindasari21@gmail.com
}

\begin{abstract}
Abstrak
Penelitian ini bertujuan untuk mendeskripsikan aspek-aspek kemampuan menulis pantun siswa kelas V SD. Metode yang digunakan peneliti adalah metode deskriptif kualitatif.Sumber data dalam penelitian ini adalah jawaban tes perbuatan pantun karya siswa kelas V SD. Teknik analisis data yang digunakan adalah validitas data dan realibilitas data. Analisis data diperoleh dari aspek-aspek kemampuan menulis pantun siswa kelas V SD yang menunjukkan bahwa (1)8 siwa yang mendapatkan kategori penilaian sangat baik dengan hasil persentase $30,76 \%$, (2) 6 siswa yang mendapatkan kategori penilaian baik dengan hasil persentase $23,07 \%$, (3) 2 siswa yang mendapatkan kategori penilaian cukup dengan hasil persentase $07,69 \%$, (4) 6 siswa yang mendapatkan kategori penilaian kurang dengan hasil persentase 23,07\%, dan (5) 4 siswa yang mendapatkan kategori penilaian gagal dengan hasil persentase $15,38 \%$. Kesimpulan dari penelitian ini bahwa rata-rata nilai siswa dalam menulis pantun yaitu 70 dengan kategori baik.
\end{abstract}

Kata kunci : analisis, menulis pantun

\begin{abstract}
Abstrack
This study aims to describe aspects of the ability to write rhymes for fifth grade elementary school students. The method used by researchers is a qualitative descriptive method. The source of the data in this study is the answer to the act of rhyme test by the fifth grade elementary school students. Data analysis techniques used are data validity and data reliability. Data analysis was obtained from aspects of the ability to write rhymes for fifth grade elementary school students which showed that (1) 8 students who received very good assessment categories with the percentage results of $30.76 \%$, (2) 6 students who got good assessment categories with percentage results of $23,07 \%$, (3) 2 students who get enough assessment categories with percentage results $07.69 \%$, (4) 6 students who get less assessment categories with percentage results of $23.07 \%$, and (5) 4 students who get assessment categories failed with a percentage of $15.38 \%$. The conclusion from this study that the average value of students in writing rhymes is 70 with a good category.
\end{abstract}

Keywords: analysis, poetry writing 


\section{PENDAHULUAN}

Salah satu mata pelajaran yang wajib diberikan di Sekolah Dasar (SD) yaitu Bahasa Indonesia. Bahasa Indonesia diarahkan untuk meningkatkan kemampuan siswa untuk berkomunikasi dalam bahasa Indonesia yang baik dan benar. Standar Isi untuk satuan pendidikan dasar dan menengah diatur dalam Peraturan Menteri Pendidikan Nasional No. 22 Tahun 2006 yang menyatakan bahwa mata pelajaran Bahasa Indonesia bertujuan agar peserta didik memiliki kemampuan sebagai berikut: (1) berkomunikasi secara efektif dan efisien sesuai dengan etika yang berlaku, baik secara lisan maupun tertulis; (2) menghargai dan bangga menggunakan bahasa Indonesia sebagai bahasa persatuan dan bahasa Negara; (3) memahami bahasa Indonesia dan menggunakannya dengann tepat dan kreatif untuk berbagai tujuan; (4) menggunakan bahasa Indonesia untuk mengingkatkan kemampuan intelektual, serta kematangan emosional dan sosial; (5) menikmatidan memanfaatkan karya sastra untuk memperluas wawasan, memperluas budi pekerti serta meningkatkan pengetahuan kemampuan berbahasa; (6) menghargai dan membanggakan sastra Indonesia sebagai khazah budaya dan intelektual manusia Indonesia (Depdiknas, 2006).

Ruang lingkup mata pelajaran Bahasa Indonesia mencakup komponen kemampuan berbahasa dan bersastra yang meliputi aspek-aspek berikut: (1) mendengarkan; (2) berbicara; (3) membaca; dan (4) menulis. Peraturan Pemerintahan No.19 Tahun 2005 tentang Standar Nasional Pendidikan Pasal 6 Ayat 6 menyebutkan bahwa kurikulum dan silabus $\mathrm{SD} / \mathrm{MI} / \mathrm{SDLB} / \mathrm{Paket} \mathrm{A}$, atau bentuk lain yang sederajat menekankan pentingnya kemampuan dan kegemaran membaca dan menulis, kecakapan berhitung, serta kemampuan berkomunikasi. Dalam Pasal 21 Ayat 2 Undang-undang yang sama menyebutkan bahwa pelaksanaan proses pembelajaran dilakukan dengan mengembangkan budaya membaca dan menulis. Hal serupa juga tertuang dalam Pasal 25 Ayat 3 Kompetensi kelulusan untuk mata pelajaran bahasa menekankan pada kemampuan membaca dan menulis yang sesuai jenjang pendidikan (Depdiknas, 2005).

Menulis adalah suatu dari empat keterampilan berbahasa Indonesia yang harus dikuasai oleh siswa.Kemampuan menulis merupakan keterampilan yang paling sulit dikuasai.Menurut Tarigan (Purwanti, 2017:53) menulis merupakan suatu kegiatan yang produktif dan ekspresif.Siswa harus terampil memanfaatkan struktur bahasa, kosakata, dan grafologi.Keterampilan dapat berkembang dengan baik melalui pembiasaan.Siswa di setiap 
jenjang pendidikan formal wajib menguasai keterampilan ini, baik berupa karya sastra maupun karya nonsastra. Kemampuan menulis tidak didapatkan secara ilmiah, tetapi harus melalui proses belajar dan berlatih. Menulis memerlukan latihan yang konsisten. Tidak ada tulisan yang baik dan menarik tanpa proses. Menulis bukan kemampuan yang diperoleh secara otomatis.Pantun adalah puisi lama yang terdiri atas empat baris bersajak ab-ab atau aa-aa.Dua baris pertama sampiran, dua baris terakhir berupa isi (Sugiarto, dalam Gafar 2014:18).

Menurut salah satu guru wali kelas V SD. Pertama, anak dikenali dulu apa itu pantun. Kedua, apasyarat pantun. Ketiga, apa bait-bait pantun. Keempat, baris 1 dan baris 2 adalah sampiran dan baris 3 dan baris 4 adalah isi.Siswa belum bisa membuat pantun sendiri masih dibimbing guru dan orang tua dirumah.Siswa membuat pantun tidak hanya berpatokan dengan buku siswa tetapi juga dengan buku lainnya.Siswa hanya bisa menulis 1 indikator yaitu syarat pantun, dari ketiga indikator pantun tersebut ialah syarat pantun, isi pantun, dan diksi.Siswa hanya bisa menulis 1 indikator yaitu syarat pantun, dari ketiga indikator pantun tersebut adalah syarat pantun, isi pantun, dan diksi.

Berdasarkan pengalaman penulis selama wawancara kelas V SD diperoleh permasalahan, yaitu (1) pantun tidak sesuai dengan syarat pantun, (2) kemenarikan isi pantun siswa kurang, (3) gaya bahasa yang kurang menarik. Menulis pantun perlu dilakukan dengan cara baru untuk memberikan kesempatan pada siswa menyampaikan tanggapan, ide, gagasan, perasaan, pengalaman, dan penghayatan agar siswa bertanggung jawab tugas yang diberikan oleh guru. Salah satu penyebab kurangnya kemampuan siswa dalam menulis pantun adalah siswa tidak mengetahui apa itu pantun dan syarat-syarat menulis pantun.

\section{TINJAUAN TEORITIS}

\section{Menulis}

Tarigan (Purwati 2017:53) menjelaskan "Menulis adalah kegiatan produktif dan ekspresif. Hal ini berarti bahwa menulis adalah proses meghasilkan sesuatu yaitu tulisan. Tulisan tersebut merupakan ekspresi dari penulisnya”.Menurut Henry Guntur Tarigan (Sardila, 2015:113-114) menyatakan bahwa menulis dapat diartikan sebagai kegiatan menuangkan ide/gagasan dengan menggunakan bahasa tulis sebagai media penyampai. 
Rukayah (Romadlon,dkk 2016:93) mengatakan bahwa menulis diartikan sebagai segenap rangkain kegiatan seseorang dalam rangka mengungkapkan gagasan dan menyampaikan melalui pesan tulis kepada orang lain agar mudah dipahami. Menulis tidak lepas dari gagasan yang diinginkan oleh penulis supaya dapat diterima oleh pembaca.

Dari pendapat para ahli, dapat disimpulkan bahwa menulis adalah proses berkomunikasi secara tidak langsung antara penulis dengan pembacanya. Tulisan dibuat untuk dipahami maksud dan tujuannya sehingga proses yang dilakukan penulis tidaklah sia-sia. Selain itu, menulis merupakan proses kegiatan pikiran manusia yang hendak mengungkapkan kandungan jiwanya kepada orang lain, atau kepada dirinya sendiri dalam bentuk tulisan.

\section{Pantun}

Pantun adalah puisi lama yang terdiri atas empat baris bersajak ab-ab atau aa-aa.Dua baris pertama sampiran, dua baris terakhir berupa isi (Sugiarto, dalam Gafar 2014:18).Menurut Wahyuni (Multafifin 2015:15) Pantun merupakan puisi lama yang mempunyai tiga ciri.Pertma, terdiri dari atas empat baris yang berpola ab-ab. Kedua, setiap baris terdiri dari 8-12 suku kata.Ketiga, dua baris pertama sebagai lampiran dan dua baris berikutnya sebagai isi.Kata "pantun” berasal dari kata patutun dalam bahasa Minangkabau yang berarti penuntun.

Menurut Pangesti (Multafifin 2015:15) Pantun merupakan salah satu jenis puisi lama yang sangat luas dikenal dalam bahasa-bahasa Nusantara.Pantun berasal dari kata patutun dalam bahasa Minangkabau yang berarti "petutun". Dalam bahasa Jawa, misalnya, dikenal sebagai parikan, dalam bahasa Sunda dikenal sebagai paparikan, dan dalam bahasa Batak dikenal sebagai umpasa (baca: uppasa). Lazimnya pantun terdiri dari atas empat larik (atau baris bila dituliskan), setiap baris terdiri dari 8-12 suku kata, bersajak akhir dengan pola a-b-ab.Pantun pada mulanya merupakan sastra lisan namun sekarang dijumpai juga pantun yang tertulis.

Pantun merupakan peninggalan masyarakat melayu yang telah ada sejak zaman dahulu kala.Oleh karena itu pantun merupakan salah satu jenis puisi lama yang sangat luas dikenal dalam bahasa-bahasa Nusantara.Pantun berasal dari kata patuntun dalam bahasa Minangkabau yang berarti penuntun.Lazimnya pantun terdiri atas empat baris setiap baris terdiri 8-12 suku kata berpola sajak a-b-a-b atau a-a-a-a. Pada baris pertama dan baris kedua disebut sampiran 
sedangkan bait ketiga dan keempat disebut isi. Bunyi pantun pada baris pertama sama dengan baris ketiga dan bunyi baris kedua sama dengan baris keempat.

\section{Jenis-Jenis Pantun}

Menurut Pangesti (Multafifin 2015:15) jenis-jenis pantun dapat dikelompokan berdasarkan isinya. Jenis-jenis pantun tersebut yaitu: (a) pantun anak-anak, (b) pantun orang muda, (c) pantun orang tua, (d) pantun teka-teki.

\section{Kemampuan Menulis Pantun}

Kemampuan menulis pantun adalah kegiatan menulis kreatif, sebab sama-sama apresiatif dan kreatif dalam menafsirkan kehidupan yang diwujudkan dalam sebuah karya tulis.Sebagian besar siswa, menulis pantun dianggap sebagai pelajaran yang sulit. Siswa harus menyusun sampiran dan isi yang dimana keduanya sama sekali tidak berkaitan dan mengunakan kalimat-kalimat yang baik. Walaupun tidak berkaitan, membuat sampiran dan isi tidak boleh asal-asalan harus bersajak a-b-a-b.

Kemampuan siswa untuk mengungkapkan idea atau gagasan dalam bentuk tulisan yang berpengaruh dalam keberhasilan menulis pantun.Pantun yang dibuat harus dapat mewakili pesan yang ingin disampaikan. 
Tabel 1 Aspek-Aspek Penilaian Menulis Pantun

\begin{tabular}{|c|c|c|}
\hline No & Aspek yang Dinilai & Skor \\
\hline \multirow{4}{*}{1} & $\begin{array}{l}\text { Kesesuaian dengan syarat pantun (Tiap bait terdiri atas } 4 \\
\text { baris, persajakan ab-ab, baris } 1 \text { dan baris } 2 \text { merupakan } \\
\text { sampiran dan baris } 3 \text { dan baris 4adalah isi) }\end{array}$ & (3) \\
\hline & $\begin{array}{l}\text { Keterangan: } \\
\text { a. Sesuai dengan syarat pantun }\end{array}$ & 3 \\
\hline & b. Sesuai dengan 2-3 syarat pantun & 2 \\
\hline & $\begin{array}{l}\text { c. Sesuai dengan } 1 \text { syarat pantun atau tidak sesuai } \\
\text { dengan semua syarat pantun }\end{array}$ & 1 \\
\hline \multirow{4}{*}{2} & Kemenarikan isi pantun & (3) \\
\hline & $\begin{array}{l}\text { Keterangan: } \\
\text { a. Isi bermakna dan memiliki pesan }\end{array}$ & 3 \\
\hline & b. Isi bermakna namun tidak memiliki pesan & 2 \\
\hline & c. Isi tidak bermakna dan tidak memiliki pesan & 1 \\
\hline \multirow{4}{*}{3} & Diksi & (3) \\
\hline & $\begin{array}{l}\text { Keterangan: } \\
\text { a. Pilihan diksi tepat yang sesuai dengan isi pantun }\end{array}$ & 3 \\
\hline & $\begin{array}{l}\text { b. Pilihan kata kurang tepat sehinnga kurang sesuai } \\
\text { dengan isi pantun }\end{array}$ & 2 \\
\hline & $\begin{array}{l}\text { c. Pilihan kata tidak tepat sehingga tidak sesuai dengan } \\
\text { isi pantun }\end{array}$ & 1 \\
\hline \multicolumn{2}{|r|}{ Jumlah } & (9) \\
\hline
\end{tabular}

Sunaryo (Gafar, 2014:23-24)

\section{METODE PENELITIAN}

Metode yang digunakan peneliti adalah analisis deskriptif kualitatif. Menurut Sugiyono (2018:15) "Metode penelitian kualitatif adalah metode penelitian yang berlandaskan pada filsafat postpositivisme, digunakan untuk meneliti pada kondisi objek yang alamiah, dimana peneliti adalah sebagai sumber sebagai instrumen kunci, pengambilan sampel sumber data dilakukan secara purposive dan snowbaal, teknik pengumpulan dengan triangulasi, analisis data bersifat 
induktif/kualitatif, dan hasil penelitian kualitatif lebih menekankan makna dari pada generalisasi”.

Data dalam penelitian ini adalah rekaman video kegiatan siswa menulis pantun.Sumber data adalah jawaban tes perbuatan, analisis kegiatan pembelajaran, hasil wawancara, hasil obsevasi dan kegiatan-kegiatan yang dilakukan oleh peneliti. Sumber data dalam penelitian ini adalah buku siswa kelas V SD, jurnal penelitian, serta hasil penelitian sebelumnya.

\section{HASIL PENELITIAN}

Hasil analisis menggunakan kriteria yang telah ditentukan dengan perolehan nilai sebagai berikut.

Tabel 2 Hasil Rekapitulasi Analisis Kemampuan Menulis Pantun Siswa Kelas VI

\begin{tabular}{|c|c|c|c|c|}
\hline No & Aspek Penilaian & $\begin{array}{c}\text { Sko } \\
\text { r }\end{array}$ & $\begin{array}{c}\text { Jumlah } \\
\text { Siswa }\end{array}$ & $\begin{array}{c}\text { Persentas } \\
\text { e }(\%)\end{array}$ \\
\hline \multirow{3}{*}{1} & \multirow{3}{*}{$\begin{array}{l}\text { Unsur-Unsur Pembangun } \\
\text { Pantun }\end{array}$} & 3 & 15 & $57,69 \%$ \\
\hline & & 2 & 6 & $23,08 \%$ \\
\hline & & 1 & 5 & $19,23 \%$ \\
\hline \multirow{3}{*}{2} & \multirow{3}{*}{$\begin{array}{c}\text { Kemenarikan Isi } \\
\text { Pantun/Amanat Pantun }\end{array}$} & 3 & 10 & $38,46 \%$ \\
\hline & & 2 & 8 & $30,77 \%$ \\
\hline & & 1 & 8 & $30,77 \%$ \\
\hline \multirow{3}{*}{3} & \multirow{3}{*}{ Diksi } & 3 & 9 & $34,62 \%$ \\
\hline & & 2 & 7 & $26,92 \%$ \\
\hline & & 1 & 10 & $38,46 \%$ \\
\hline
\end{tabular}

(Sumber: Hasil penelitian,2020) 


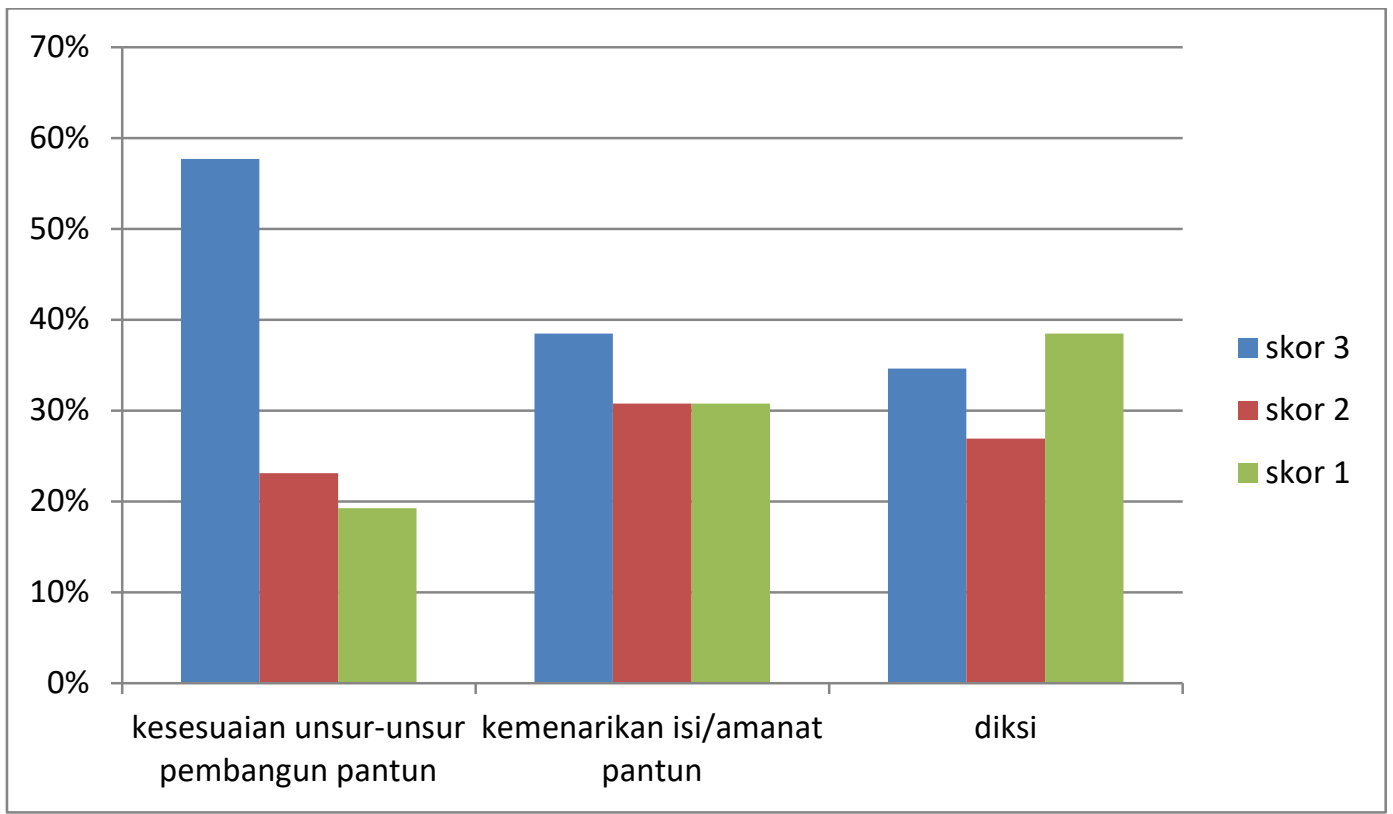

(Sumber: Hasil Penelitian, 2020)

\section{Gambar 1}

Diagram Hasil Rekapitulasi Analisis Kemampuan Menulis Pantun Siswa Kelas VI

Tabel 3 Jumlah Siswa berdasarkan Kategori Penilaian

\begin{tabular}{|c|c|c|c|}
\hline No & Jumlah Siswa & Kategori Penilaian & $\begin{array}{c}\text { Persentase } \\
(\boldsymbol{\%})\end{array}$ \\
\hline 1 & 8 & Sangat Baik & $30,76 \%$ \\
\hline 2 & 6 & Baik & $23,07 \%$ \\
\hline 3 & 2 & Cukup & $07,69 \%$ \\
\hline 4 & 6 & Kurang & $23,07 \%$ \\
\hline 5 & 4 & Gagal & $15,38 \%$ \\
\hline
\end{tabular}




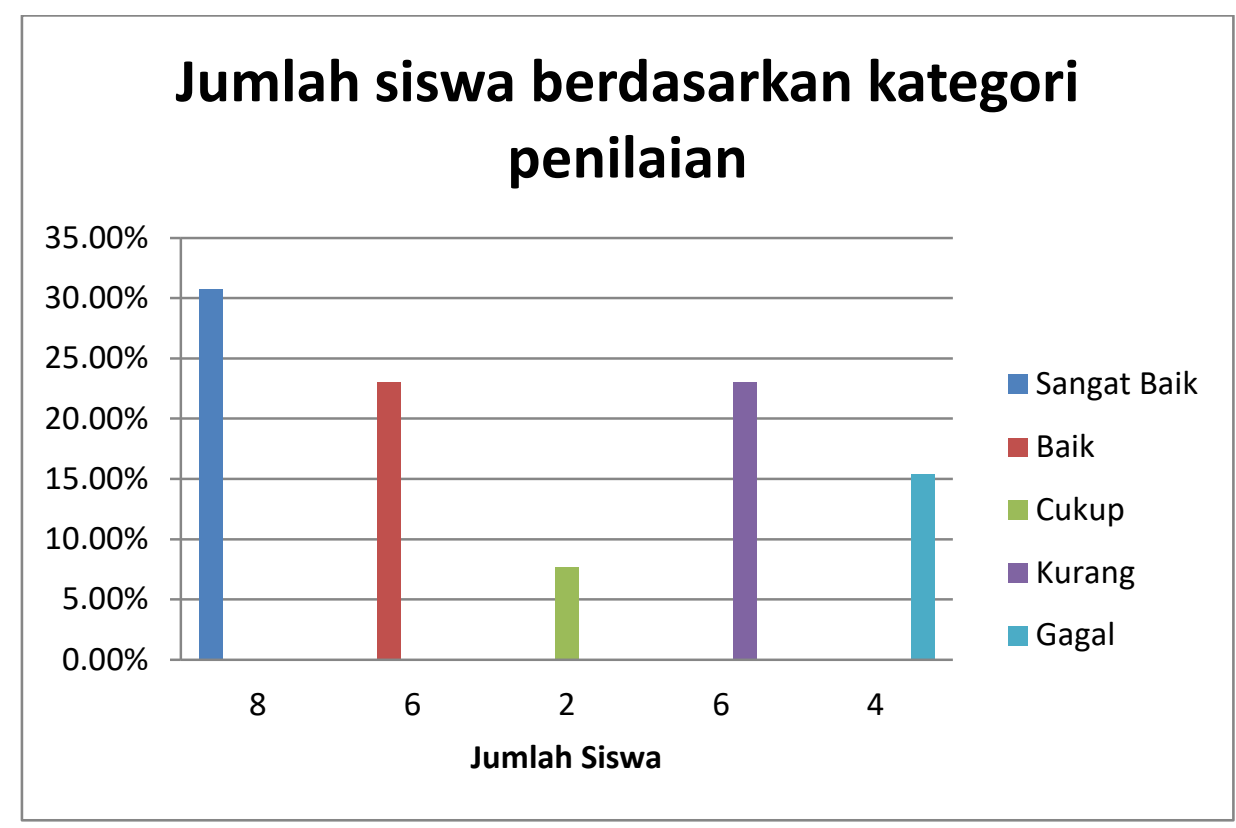

(Sumber: Hasil Penelitian, 2020)

\section{Gambar 2 Diagram Jumlah Siswa berdasarkan Kategori Penilaian}

Dilihat dari kesesuain unsur-unsur pembangun pantun.Ada beberapa unsur-unsur pembangun pantun, yaitu tiap bait terdiri atas 4 baris, persajakaan ab-ab, baris 1 dan baris 2 merupakan sampiran dan baris 3 dan baris 4 merupakan isi. Hasil analisis kemampuan dalam menulis pantun dilihat dari aspek unsur-unsur pembangun pantun pada siswa kelas VI SD yang berjumlah 26 siswa persentase dari aspek kesesuaian dengan unsur-unsur pembangun pantun yaitu, siswa yang mendapatkan skor 3 sebanyak 15 siswa dengan persentase 57,69\%.

Hasil analisis kemampuan dalam menulis pantun dilihat dari aspek kemenarikan isi/amanat pantun siswa kelas VI SD yang berjumlah 26 siswa persentase dari aspek kemenarikan isi/amanat pantun yaitu, siswa yang mendapatkan skor 3 sebanyak 10 siswa dengan persentase 38,46\%.Hal ini membuktikan bahwa siswa paham dengan isi/amanat pantun yang ditulis. Siswa yang mendapatkan skor 2 sebanyak 8 siswa dengan persentase $30,76 \%$.

Dilihat dari diksi. Ada beberapa aspek yang penting, yaitu pilihan kata, struktur dan gaya bahasa. Hasil analisis kemampuan dalam menulis pantun dilihat dari aspek diksi pantun siswa kelas VI SD yang berjumlah 26 siswa persentase dari aspek diksi pantun yaitu, siswa yang mendapatkan skor 3 sebanyak 9 siswa dengan persentase $34,62 \%$. 


\section{KESIMPULAN}

Dari hasil penelitian disimpulkan bahwa rata-rata nilai siswa dalam menulis pantun yaitu 70 dengan kategori baik. Maka, 8 siwa yang mendapatkan kategori penilaian sangat baik dengan hsil persentase 30,76\%, 6 siswa yang mendapatkan kategori penilaian baik dengan hasil persentase 23,07\%, 2 siswa yang mendapatkan kategori penilaian cukup dengan hasil persentase 07,69\%, 6 siswa yang mendapatkan kategori penilaian kurang dengan hasil persentase 23,07\%, dan 4 siswa yang mendapatkan kategori penilaian gagal dengan hasil persentase 15,38\%.

Selaras dengan hasil peneliti yaitu, kurang berhasilnya siswa dalam menulis pantun karena, guru mengajarya secara keseluruhan, guru kurang mengajarnya tentang diksi dalam pantun dan menggunakan pantun yang sudah ada. Hal ini dibuktikan hasil wawancara peneliti dengan salah satu wali kelas V SD yaitu kebanyakan siswa membuat pantun masih bingung dan perlu bimbingan guru atau wali murid dan juga siswa hanya berpatokaan dengan buku siswa tetapi ada juga dengan buku lainnya.

Berdasarkan kesimpulan diatas guru disarankan dalam proses pembelajaran ada sebaiknya guru mengunakan media yang menarik dan membuat siswa berperan aktif dalam proses pembelajaran agar tujuan pembelajaran tercapai, dan juga dalam pembelajaran menulis pantun, guru disarankan jangan menggunakan pantun yang lama, tetapi gunakanlah pantun yang baru, agar pengetahuan siswa dalam menulis pantun berkembang aktif.

\section{DAFTAR PUSTAKA}

Depdiknas. (2005). Peraturan Menteri Pendidikan Nasional No.19 Tahun 2005 Tentang Standar Nasional Pendidikan. Jakarta: Depdiknas.

Depdiknas. (2006). Peraturan Menteri Pendidikan Nasional Nomor 22 Tahun 2006 Tentang Standar Isi untuk Satuan Pendidikan Dasar dan Menengah. Jakarta: Depdiknas.

Gafar, Abdoel. (2014). Kemampuan Menulis Pantun dengan Model Pembelajaran Quantum Teaching Pada Siswa Kelas VII.C SMP Negeri 16 Kota Jambi Tahun Ajaran 2014/2015. Vol.4 No.2 Desember 2014.

Multafifin. (2015). Kemampuan Menulis Pantun Siswa Kelas VII SMP Negeri 52 Konawe Selatan. Jurnal Hamanika No.15, Vol.3, Desember 2015

Purwati, Dewi. (2017). Peningkatan Kemampuan Menulis Pantun dengan Menggunakan Model Berpikir Berbicara Menulis (Think Talk Write).Jurnal Diksatrasia Volume 1, Nomor 2, Agustus 2017. 
Romadlon, Muhammad Rizqi. dkk. (2016). Peningkatan Keterampilan Menulis Puisi dengan Model Snowball Throwing dan Media Pohon Kata Pada Siswa Kelas VII E Negeri 16 Surakatra. Volume 1, Nomor 1, Agustus 2016

Sardila, Vera. (2015). Strategi Pengembangan Linguistik Terapan Melalui Kemampuan Menulis Biografi dan Autobiografi: Sebuah Upaya Membangun Keterampilan Menulis Kreatif Mahasiswa.Jurnal Pemikiran Islam, Vol.40, No.2 Juli-Agustus 2015.

Sugiyono. (2018). Metode Penelitian Pendidikan Pendekatan Kuantitatif, Kualitatif, dan R\&D. Bandung: ALFABETA. 